\title{
Peran Digital Marketing dalam Upaya Meningkatkan Omset Penjualan Tenun Endek dan Songket Desa Telaga Tawang
}

\author{
The Role of Digital Marketing in an Effort to Increase the Sales Turnover of Endek and Songket \\ Weaves in Telaga Tawang Village
}

Anak Agung Istri Agung
Maheswari"
Nanda Dwi Azhizah
Ifan Nugraha
Made Pradnyan Hary N
Department of Management,
Universitas Pendidikan Nasional,
Denpasar, Bali, Indonesia
"email: agungmaheswari@gmail.com
Kata Kunci
Digital
Pemasaran
Tenun
Keywords:
Digital
Marketing
Weaving
Received: February 2020
Accepted: June 2020
Published: September 2020

\begin{abstract}
Abstrak
Salah satu mata pencaharian masyakat Desa Telaga tawang adalah menjadi penenun Endek dan Songket. Akan tetapi masyarakat hanya sebagai pekerja karena biaya yang dibutuhkan untuk membeli perlengkapan dan peralatan tenun cukup besar, karna hal itu pemilik usaha Arta Sedana memberikan modal berupa perlengkapan supaya masyarakat memiliki pekerjaan dan mendapatkan penghasilan.Peranan Digital marketing dalam upaya peningkatan omset penjualan tenun endek dan songket, kami memberikan arahan tentang bagaimana mempromosikan produk tenun endek dan songket secara Direct marketing. Promosi tersebut bisa dilakukan melalui media sosial seperti Email, isntagram, facebook, dan WhatsApp. Kami juga membantu membuatkan akun media sosial dan memberi tahu bagaimana cara menggunakan akun media sosial untuk memasarkan produk. Metode kegiatan yang kami lakukan adalah dengan memberikan penyuluhan kepada kelompok usaha Arta Sedana dengan memberi tahu bagaimana peluang usaha dalam memanfaatkan Digital Marketing. Maka dari itu solusi yang dapat kami berikan adalah dengan memberikan arahan untuk membuat akun sosial media atau yang berkaitan dengan digital marketing.
\end{abstract}

\begin{abstract}
One of the livelihoods of the people of Telaga tawang Village is to become an Endek and Songket weaver. However, the community is only a worker because the costs needed to buy weaving equipment and equipment are quite large, because of that Arta Sedana business owner provides capital in the form of equipment so that people have a job and earn income. The role of digital marketing in an effort to increase sales turnover of endek and songket weaving, we provide direction on how to promote endek and songket woven products in direct marketing. This promotion can be done through social media such as E-mail, Instagram, Facebook and WhatsApp. We also help create social media accounts and tell you how to use social media accounts to market products. The method of activity we do is to provide counseling to the Arta Sedana business group by telling them how business opportunities are in utilizing digital marketing. Therefore, the solution we can provide is to provide directions for creating social media accounts or those related to digital marketing.
\end{abstract} Open Access article under the CC-BY-SA License (http://creativecommons.org/licenses/by-sa/4.0/). DOI: https://doi.org/10.33084/pengabdianmu.v5i4.1258

\section{PENDAHULUAN}

Usaha mikro, kecil, dan menengah atau biasa disingkat UMKM adalah unit usaha produk yang berdiri sendiri, yang dilakukan orang perorangan atau badan usaha disemua sektor ekonomi secara garis besar penentuan usaha mikro kecil dan menengah ditentukan dengan nilai asset (tidak termasuk tanah dan bangunan) (Ramandhana et al., 2018; Nurbudiyani et al., 2019). Tenun merupakan teknik dalam pembuatan kain yang 
dibuat dengan prinsip yang sederhana yaitu dengan, menggabungkan benang secara memanjang dan melintang (Hendraswati, 2018; Wasri et al., 2017).

Salah satu mata pencaharian masyakat Desa Telaga tawang adalah menjadi penenun Endek dan Songket. Akan tetapi, masyarakat hanya sebagai pekerja karena biaya yang dibutuhkan untuk membeli perlengkapan dan peralatan tenun cukup besar, karna hal itu pemilik usaha Arta Sedana memberikan modal berupa perlengkapan supaya masyarakat memiliki pekerjaan dan mendapatkan penghasilan. Untuk meningkatkan penjualan serta pemasaran produk tenun endek dan songket desa telaga tawang yaitu dengan menggunakan social media sebagai wadah untuk promosi atau memperkenalkan produk tenun desa telaga tawang (Untari \& Fajariana, 2018; Suryani, 2014). Agar penjualan Endek dan Songket dari UMKM Arta Sedana bisa dikenal di seluruh Bali juga di kancah nasional ataupun internasional.

Berdasarkan pemaparan latar belakang diatas, maka permasalahan yang akan dibahas dalam pengabdian masyrakat ini adalah peran digital marketing dalam upaya peningkatan omset penjualan tenun endek dan songket desa telaga tawang. Tujuan dari pengabdian masyarakat ini adalah memberikan pemahaman tentang peran digital marketing untuk upaya meningkatkan omset penjualan tenun endek dan songket desa telaga tawang.

\section{METODOLOGI}

Metode kegiatan yang kami lakukan adalah dengan memberikan penyuluhan kepada kelompok usaha Arta Sedana dengan memberi tahu bagaimana peluang usaha dalam memanfaatkan Digital Marketing. Maka dari itu yang dapat kami berikan adalah dengan memberikan arahan untuk membuat akun social media atau yang berkaitan dengan digital marketing. Untuk meningkatkan penjualan serta pemasaran produk tenun endek dan songket yaitu dengan menggunakan digital marketing seperti media sosial sebagai wadah untuk promosi atau memperkenalkan produk tenun desa telaga tawang dengan tujuan agar produk yang dijual bisa menjangkau pasar konsumen lebih luas serta mempermudah konsumen untuk mengetahui produk tenun endek songket itu sendiri.

\section{HASIL DAN PEMBAHASAN}

Peranan Digital marketing dalam upaya peningkatan omset penjualan tenun endek dan songket, kami memberikan arahan tentang bagaimana mempromosikan produk tenun endek dan songket secara Direct marketing. Promosi tersebut bisa dilakukan melalui media sosial seperti Email, Instagram, Facebook, dan WhatsApp. Kami juga membantu membuatkan akun media sosial dan memberi tahu bagaimana cara menggunakan akun media sosial untuk memasarkan produk. Kini Direct Marketing menjadi pasar sasaran untuk konsumen karena media elektronik yang semakin diminati, karena tersedianya berbagai macam media sosial yang dapat digunakan untuk mempromosikan produk. Dokumentasi kegiatan penyuluhan disajikan pada Gambar 1.

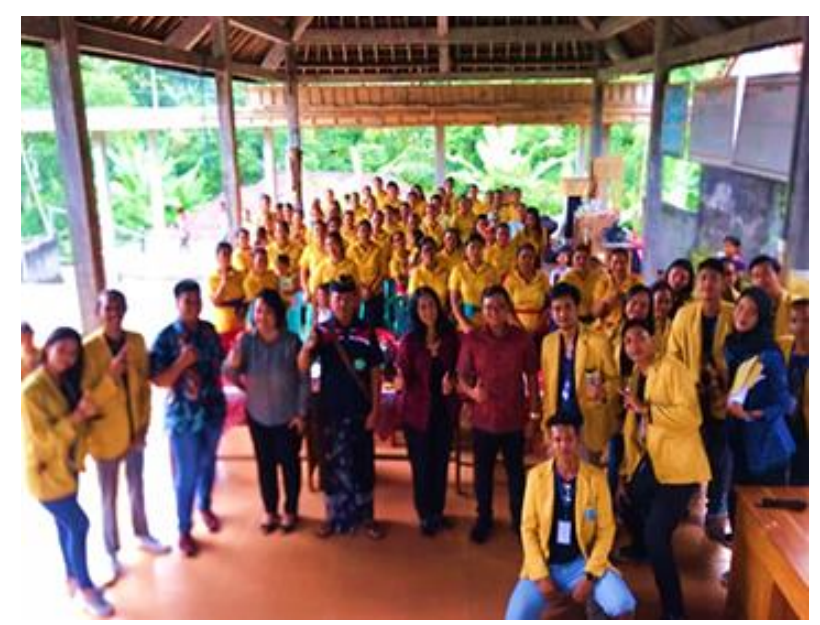

Gambar 1. Penyuluhan kepada kelompok usaha Arta Sedana 
Tampilan dari akun Instagram, Facebook, dan Email yang kami buat untuk mempermudah kelompok Arta Sedana memasarkan produk tenun endek dan songket disajikan sebagai berikut:

\section{Email}

Sebelum kami membuat akun media sosial Instagram dan Facebook, kami membuat akun email untuk digunakan sebagai alamat email yang dicantumkan saat membuat akun Instagram dan Facebook. Keunggulan email ini juga memudahkan untuk mengirim foto produk dengan kualitas foto yang jelas (HD) sehingga konsumen bisa melihat lebih jelas bagaimana kualiatas produk (Putro et al., 2014). Email ini juga bisa digunakan misalnya mendapatkan permintaan dengan jumlah besar sehingga terdapat file surat perjanjian kontrak pembelian produk atau file-file yang berkaitan dengan penjualan (Santoso \& Indriyani, 2015). Tampilan email yang dibuat disajikan pada Gambar 2.

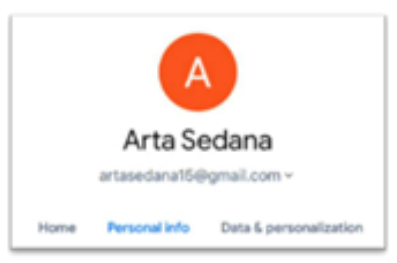

Gambar 2. Alamat email Kelompok usaha Arta Sedana

\section{Media sosial Instagram}

Di Indonesia, jumlah pengguna Instagram aktif mencapai 22 juta orang, sehingga menentukan bahwa pemasaran dengan menggunakan media sosial instagram memiliki peluang besar untuk memasarkan sebuah produk. Dengan memaksimalkan penggunaan Instagram sebagai media pemasaran produk bisa meningkatkan omset penjualan dan pada akhirnya omset penjualan bisa naik dari sebelum sebelumnya (Atmoko, 2018; Utomo et al., 2019).

Maka dari itu kami membuat akun Instagram sebagai media pemasaran dari produk tenun endek dan songket, dan media ini salah satu dari peran digital marketing dalam pemasaran produk. Tidak hanya membuat akun, kami membuat tampilan produk semenarik mungkin agar bisa menarik konsumen. Tampilan Instagram yang telah dibuat disajikan pada Gambar 3.

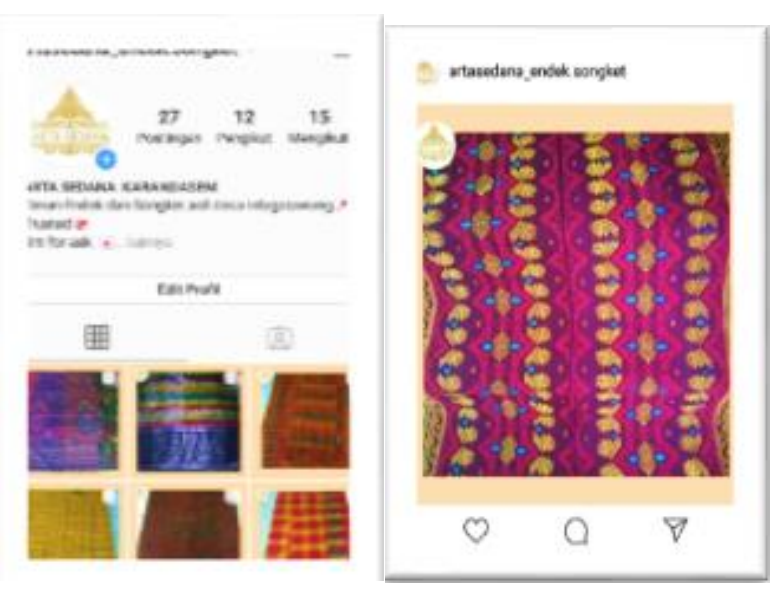

Gambar 3. Akun Instagram Kelompok usaha Arta Sedana

\section{Media sosial Facebook}

Akun media sosial selanjutnya yang kami buat adalah Facebook, pengguna Facebook juga tidak kalah banyak dengan pengguna Instagram (Permata, 2017). Maka dari itu kami juga membuat akun Facebook sebagai media sosial selanjutnya yang kami pilih sebagai media pemasaran dari produk Arta Sedana, tidak hanya itu media sosial Facebook lebih umum dan lebih mudah digunakan. Tampilan Facebook yang telah dibuat disajikan pada Gambar 4.
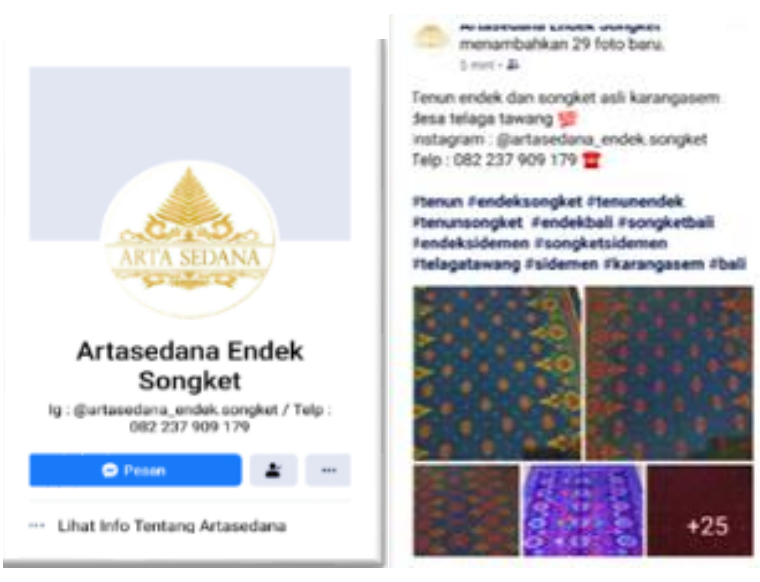

Gambar 4. Akun Facebook Kelompok usaha Arta Sedana 
Penyuluhan Peran digital marketing dalam upaya meningkatkan omset penjualan tenun endek dan songket di desa telaga tawang. Dengan adanya peranan digital marketing dalam pemasaran dan penjualan produk maka akan membantu menaikkan omset penjualan produk tenun serta menarik konsumen pasar secara luas (Pambudi \& Suyono, 2019). Harapan kami dengan adanya peran digital marketing dalam usaha produk tenun endek dan songket bisa membantu memasarkan produk tenun lebih banyak lagi dan memperkenalkan produk secara lebih meluas kepada konsumen. Tabel Perbandingan sebelum dan sesudah dilaksanakan kegiatan disajikan pada Tabel I.

Tabel I. Karakteristik Peserta

\begin{tabular}{cll}
\hline No & \multicolumn{2}{c}{$\begin{array}{l}\text { Perbandingan Sebelum dan Sesudah Penyuluhan Tenun } \\
\text { Sebelum }\end{array}$} \\
\hline $\mathbf{1}$ & $\begin{array}{l}\text { Kelompok Arta Sedana } \\
\text { masih belum paham } \\
\text { bagaimana memasarkan } \\
\text { produk tenun secara } \\
\text { meluas. }\end{array}$ & $\begin{array}{l}\text { Kelompok Arta Sedana sudah } \\
\text { mulai paham bagaimana } \\
\text { memasarkan produk dengan } \\
\text { menggunakan peran media } \\
\text { digital marketing seperti } \\
\text { instagram dan facebook. }\end{array}$ \\
$\mathbf{2}$ & $\begin{array}{l}\text { Masih banyak yang } \\
\text { belum mengetahui } \\
\text { tentang produk tenun } \\
\text { endek dan songket dari } \\
\text { kelompok Arta Sedana } \\
\text { Penjualan produk tenun mengetahui dari produk } \\
\text { masih terbilang sedikit }\end{array}$ & $\begin{array}{l}\text { Penjualan produk meningkat } \\
\text { dan jumlah yang dijual } \\
\text { melebihi dari sebelumnya }\end{array}$ \\
\hline
\end{tabular}

\section{KESIMPULAN}

Kegiatan KKN kami terkait dengan memberikan penyuluhan tentang peran digital marketing sebagai media untuk meningkatkan omset penjualan tenun endek dan songket desa telaga tawang adalah dengan peran digital marketing sebagai media pemasaran sangat penting karena di era saat ini. Dengan adanya akun sosial media Instagram dan Facebook yang kami buat bisa dipergunakan dengan baik dan maksimal oleh kelompok usaha Arta Sedana, dan apabila nantinya sudah paham untuk mengelola Instagram dan Facebook secara maksimal, kelompok Arta Sedana bisa menggunakan media digital marketing lainya sebagai usaha pemasaran produk mereka secara lebih meluas lagi dari sebelumnya.

\section{UCAPAN TERIMA KASIH}

Dalam penyusununan jurnal pengabdian masyarakat mendapat saran dan dorongan dari berbagai pihak sehingga dalam kesempatan ini perkenankan penulis mengucapkan terimakasih sebesar-besarnya kepada dosen pembimbing, kepala desa, seluruh staf Desa Telaga tawang dan kepada pemilik UMKM Arta Sedana yang sudah membantu selama berlangsungnya kuliah kerja nyata Universitas Pendidikan Nasional.

\section{REFERENSI}

Atmoko, T.P.H. 2018. Strategi Pemasaran Untuk Meningkatkan Volume Penjualan Di Cavinton Hotel Yogyakarta. Journal of Indonesian Tourism, Hospitality and Recreation. 1(2):83-96. https://doi.org/10.17509/jithor.v1i2.13769

Hendraswati. 2018. Proses Produksi, Fungsi, Peluang Ekonomi, Dan Pengembangan Tenun Bugis Pagatan Kabupaten Tanah Bumbu Kalimantan Selatan. Handep: Jurnal Sejarah dan Budaya. 1(2):35-58. https://doi.org/10.33652/handep.v1i2.45

Nurbudiyani, I., Sonedi, Suyati, E.S., Pratama, M.R.F. 2019. Development of Micro, Small and Medium Enterprises Rattan Woven Crafts in Central Kalimantan, Indonesia. Anterior Jurnal. 18(2):132-142.

https://doi.org/10.33084/anterior.v18i2.533

Pambudi, B.S., Suyono, S. 2019. Digital Marketing As An Integrated Marketing Communication Strategy In Badan Usaha Milik Desa (BUMDesa) In East Java. Competence : Journal of Management Studies (Kompetensi : Jurnal Studi Manajemen).

13(2):121-151. https://doi.org/10.21107/kompetensi.v13i2. 6829

Permata, A.A. 2017. Pemanfaatan media sosial untukjual beli online di kalangan mahasiswa fisip universitas airlangga surabaya melalui Instagram. Libri-Net. 6(1):9-10. 
Putro, S.W., Semuel, H., Brahmana, R.K.M.R. 2014. Pengaruh Kualitas Layanan dan Kualitas Produk Terhadap Kepuasan Pelanggan dan Loyalitas Konsumen Restoran Happy Garden. Jurnal Manajemen Pemasaran. 2(1):1-9.

Ramandhana, D.Y., Jayawarsa, A.A.K., Aziz, I.S.A. 2018. Pengaruh Inflasi, Suku Bunga BI Rate, Pertumbuhan Ekonomi, Non Performing Loan (NPL) dan Capital Adequacy Ratio (CAR) terhadap Penyaluran Kredit Usaha Rakyat (KUR) pada Bank Umum di Indonesia Periode 2013-2017. Warmadewa Economic Development Journal (WEDJ). 1(1):30-40. https://doi.org/10.22225/wedj.1.1.1117.30-40

Santoso, N.H., Indriyani, R. 2015. Analisa Strategi Bersaing PT. X. Agora, Jurnal Mahasiswa Manajemen Bisnis. 3(2):430-438.

Suryani, I. 2014. Pemanfaatan Media Sosial sebagai Media Pemasaran Produk dan Potensi Indonesia dalam Upaya Mendukung ASEAN Community 2015. (Studi Social Media Marketing Pada Twitter Kemenparekraf RI dan Facebook Disparbud Provinsi Jawa Barat). Jurnal Komunikasi. 8(2):123-138.

Untari, D., Fajariana, D.E. 2018. Strategi Pemasaran Melalui Media Sosial Instagram (Studi Deskriptif Pada Akun @Subur_Batik). Widya Cipta : Jurnal Sekretari dan Manajemen. 2(2):271278.

https://doi.org/10.31294/widyacipta.v2i2.43 87

Utomo, S.H., Qurrata, V.A., Purnamasari, V., Seprillina, L. 2019. Peningkatan Omset Penjualan Melalui Media Sosial Pada Usaha Kecil Menengah Alas Kaki Berbahan Kulit. Jurnal Karinov. 2(1):57-61. http://dx.doi.org/10.17977/um045v2i1p5761

Wasri, N., Minarsih, Erwin, A. 2017. Penerapan Motif Tenun Pandai Sikek Sebagai Elemen Estetis Produk Houseware Melalui Alat Tenun Bukan Mesin (ATBM). Serupa : The Journal of Art Education. 6(1):1-20. 